\title{
Exploration of Think-Pair-Share Varieties of Reading Comprehension
}

\author{
Pavida Naksathit ${ }^{1 *}$ Punwalai Kewara ${ }^{2}$ \\ 1. Faculty of Education, Burapha University, 169 LongHad Bangsaen RD, Chonburi 20131, Thailand \\ 2. Faculty of Education, Burapha University, 169 LongHad Bangsaen RD, Chonburi 20131, Thailand \\ * E-mail of the corresponding author: dreampavida@gmail.com
}

\begin{abstract}
The study was a classroom action research aimed to explore the phenomenon in each variety of the Think-PairShare (TPS) technique in reading comprehension, and to propose a TPS model in reading comprehension. Twentytwo learners in grade 12 (17-18 years old) were selected by purposive sampling method. The qualitative data collection included four lesson plans which were conducted to teach reading comprehension and the different patterns of the TPS technique were implemented in each lesson plan. Then, the learners studied with the adapted lesson plans. The teacher simultaneously observed and video recorded the class. This was to examine the phenomenon in each stage of the TPS technique. Lastly, the researcher noted the reflections immediately after class. The data collection was divided into four sessions, each session was implemented with a different pattern of the TPS technique. The findings revealed that the appropriate proposed TPS model in teaching reading comprehension was (1) The "Think" stage is for answering the pre-reading questions. This activity could promote the learners' individual thinking process. The appropriate time duration for this stage is ten minutes. (2) The "Pair" stage is for the learners to read the text, comprehend the text, and do the task in pairs. The appropriate pattern of pair dyadic was independent partner which means the learner chose their partner for themselves. This style of dyadic lead to high collaboration in each pair. (3) The appropriate method of sharing for the "Share" stage was answering the post-reading questions. It was not time-consuming; the teacher could examine all the learners' comprehension at the same time. The learners had a chance to get feedback and revise their ideas.
\end{abstract}

Keywords: The Think-Pair-Share technique, reading comprehension, Time duration of "Think", Pattern of Pair configuration, Method of sharing.

DOI: $10.7176 / \mathrm{JEP} / 11-6-27$

Publication date: February $29^{\text {th }} 2020$

\section{Introduction}

Reading comprehension is a level of comprehending reading material (Rayner, Foorman, Perfetti, Pesetsky, and Seidenberg, 2001). It is an essential skill that L2 learners need to acquire if they are to attain mastery of the language (Bond, 1989). However, the previous studies of EFL and ESL reading revealed that there are many difficulties and challenges in teaching reading skills to the students which should be improved.

Problems like pronunciation, punctuation awareness, and inefficient reading strategies are the challenges in reading comprehension. The participants' culture, their negative attitude, and the failure in teaching phonic skills also influenced the challenges in reading comprehension (Alsubaie, 2014). Moreover, most of the EFL learners had difficulties in reading comprehension at the level of pronunciation and ambiguous words, as well as the nature of the selected materials (Medjahdi, 2015).

Furthermore, from the researcher's teaching experience, I frequently encountered students' reading problems. Some of their problems are similar to the findings mentioned earlier; it was found that Thai students often struggle with reading. Limited vocabulary and grammatical knowledge, inability to comprehend the text and grasp the main ideas are their major problems (Adunyarittigun, 2002). This corresponds to Narkprom, Poosiripinyo, and Saito (2016) who proposed that when the students read the text, they cannot read smoothly. They often encounter unknown words and unfamiliar grammar structures. They also have problems with pronunciation and punctuation awareness. After observing my own reading class, it was noticed that the students' motivation in learning was low, they looked tired and bored. Moreover, their inadequate background knowledge related to the topic of the texts is one of the important problems that they faced.

From the above information about difficulties in reading comprehension, it is indicated that this reading skill should be improved. In this study, the researcher is interested in using the Think-Pair-Share technique to improve 
students' reading skills. According to Sari (2012), the use of TPS could improve her L2 students' reading skills. The students are able to infer the meaning of the words, identify the main idea of the text, identify the reference of the text, find implicit information of the text, determine explicit information, and identify the communicative purpose of the text. Moreover, the class situation has changed in a positive way. Most of the students were active and communicative during the teaching and learning process, they began to be more enthusiastic in reading class without bothering their classmates. They also have higher motivation and interest in joining the reading class. Therefore, in this study, the researcher believed or assumed that the TPS technique can improve students' reading skill.

Think-Pair-Share is a low-risk strategy to get many students actively involved in classes of any size. It is also a strategy that encourages student classroom interaction; it encourages a high degree of pupil responses and helps keep students on task. There are three stage of TPS; Think-think about your answer individually, Pair-pair with a partner and discuss your answer, and Share-share your or your partners' answer. The teachers can use this technique in the classroom with the aim of interacting and communicating (Ledlow, 2001).

However, the TPS technique is not one fixed model. There are no researchers that confirm that one pattern of TPS can fit with all types of classroom contexts. The effectiveness of using TPS techniques can be different if we use a different duration of time during the Thinking stage, the varieties of pairing configuration, and the various methods of sharing.

Therefore, this research was conducted to explore the phenomenon in each "Think", "Pair", and "Share" variety in the TPS technique in reading comprehension. Focusing on the time duration of "Think", patterns of "Pair" configuration, and methods of "sharing" the ideas. The objective of this study is to examine an appropriate Think-Pair-Share model in reading comprehension for Grade 12 students.

\subsection{Conceptual Framework}

Think-Pair-Share is a well-known technique which is one of the cooperative learning strategies. Lyman (1992) stated that it aims to encourage students to participate in class. This technique also stimulates the students to collaborate in the classroom, exchange and discuss their ideas, and share with their classmates. Moreover, ThinkPair-Share is a low-risk strategy, teachers can get many students actively involved in classes of any size (Ledlow, 2001). The effectiveness of using the TPS technique with reading classes has been investigated by many researchers such as Lasnami (2013) whose study revealed that by using the TPS technique, the interaction of the students significantly increased. Also, the TPS technique increased the students' personal communication which was important for them to understand, organize, retain ideas and learn from each other. It can be concluded that the students were active when using TPS. It was better than those who worked alone, and the technique also provided students with more chances to talk and interact. Similarly, Maulida (2017) conducted a study entitled "The use of Think-Pair-Share in teaching reading comprehension." The findings revealed that the use of the TPS technique could increase the students' confidence. They might hesitate to come forward voluntarily if they were alone but it was in contrast with the pair work. They would be brave enough to show their ideas to others. Furthermore, the students became more active and creative when TPS was implemented in the class.

Moreover, Fatkur (2017) examined the effectiveness of the TPS technique to teach reading comprehension. The findings showed that the TPS technique not only gave opportunities for students to improve their reading comprehension but it also stimulated the students' motivation in reading. All students participated in classroom activities. They were able to communicate with their partner and friend to solve the problems related to the posed questions. They had a chance to speak, shared their own perspective, and developed their skill in working with other. They could improve their confidence by sharing their brief ideas to their classmates. This made the class come alive and cooperative. The students became more confident as well.

According to Ledlow (2001), the TPS technique can be divided into three steps. First, students work individually; second, students work with a partner. They tell or describe their own idea from the first step with their partner. The last step is discussing with the whole class and sharing the knowledge that they gained as a group member. This can be concluded that the TPS technique consists of individual work, pair work, and whole-class discussion.

In this study, the researcher implemented the TPS technique in order to boost students' basic skills of reading comprehension in class. Durkin (1993) explained that reading comprehension is the active process of constructing meaning from text. This is analogous to Pressley (2000) and Birsch (2011) who stated that reading comprehension is the ability to get meaning from what is read. It is a complicated process in which readers have an essential role 
in making meaning from the text by applying existing skills (Block, 2004). It can be summarized that reading comprehension is the basic skill for the learners in order to read and understand the text. A reading lesson, in which the readers intend to grasp the meaning of new information based on what the readers already know, think or feel about the topic, is divided into three stages namely the pre-reading stage, while-reading stage, and post-reading stage, respectively (Wahjudi, 2010).

The pre-reading stage is the stage that the teacher works on general aspects of the topic, this is dedicated to elicit the students' background knowledge about the topic and prepare them to be ready for new information (Wahjudi, 2010). Pre-questioning is one of the activities used during the pre-reading stage. The teacher and students start asking some questions, guessing answers, and drawing some inferences before reading begins (Rasheed, 2014). Applying this activity into the class, allowed the participants in this study to follow the "Think" stage from the TPS technique by thinking individually along with the posed questions.

While-reading is the stage that the students generally read the text with some purposes or interest in mind (Wahjudi, 2010). During this stage, the participants in this study get the opportunity to read, to comprehend the text, and to do the task work in pair mode. This is part of the TPS technique. However, Storch (2002) revealed that the students can scaffold each other's performance when working in pairs, but it will occur when pairs interact in the right pattern. This study specifies three patterns of pair configuration to find out the appropriate pattern of pair configuration that the member in each pair can work together.

The three patterns include: (1) independent partner, the students have a chance to pair up independently; (2) Dominant/Dominant, when there may be very little engagement with each other's contribution in each pair (Storch, 2002). This pattern is for the students working together who have the same effectiveness in the English language; and (3) Dominant/Passive, which means the teacher pairs the authoritarian students with the lower skill students (Storch, 2002).

The post-reading stage is provided to the teacher in order to assess the students' comprehension of the passage or continue to build their comprehension by using activities which require students to reflect on the main ideas, to share ideas, and return to the text (Aebersold \& Field, 2003 as cited in Gumus, 2009). In this study, the researcher is interested in three post-reading activities; asking questions, doing mind-mapping, and retelling the passage. These activities allow students to do the "share" stage from the TPS technique. It gives the teacher a chance to examine students' ability in comprehending the texts and the students can get feedback and revise their ideas.

In this study, four lesson plans were presented as a research instrument. The TPS technique was implemented in the lesson plans. These TPS lesson plans were used to explore the phenomenon in each facet of the Think-PairShare technique (TPS) in reading comprehension. According to Wahjudi (2010), each lesson plan was divided into three stages; pre-reading, while-reading, and post-reading. Therefore, in this study the pre-reading stage was used for checking the students' background knowledge and allowing the students to do the "Think" step. While-reading stage was for "pairing". The students were asked to pair with a partner in the various patterns of pair configuration then work together. The post-reading stage was for the students to "Share" their ideas or their understanding of the text to their classmates.

From the above information, it was found that many researchers examined the use of TPS in a reading context. All the findings can lead to the conclusion that TPS can improve students' reading comprehension skill and the class situation was changed in a positive way. Therefore, in this study, the researcher believed that TPS can also improve Thai students' reading skill. Therefore, the researcher decided to explore the phenomenon of using varieties of Think, Pair and Share in the reading comprehension classroom to find the appropriate Think-PairShare model in reading comprehension Then, proposed a TPS model in teaching reading comprehension. Consequently, this study may be helpful for teachers who struggle with teaching reading skill.

\section{Literature Review}

This part provides information and presents the theoretical and research literature related to the present study. All topics in this chapter contain previous studies from Thailand and abroad in order to deal with the implementation of the Think-Pair-Share technique to the reading contexts. The review is divided into the following categories

\subsection{Think-Pair-Share technique}

Think-Pair-Share technique is a part of cooperative learning. Bell (1988) described that TPS is a technique that was developed by Frank Lyman in 1981. This technique is to stimulate the students' interacting and communicating in the classroom. It is designed to provide students with given topics, enabling them to formulate individual ideas and share ideas with another student. The TPS technique also is used to encourage students to think, participate, 
and exchange ideas to other classmates.

Implementing the TPS technique into the classroom, the teachers do not spend much time in preparation. Moreover, it makes a classroom more productive. The students have an opportunity to think before sharing their ideas to their classmates, students gain self-confidence when sharing ideas to the whole class. The pair step helps to ensure that all the students are included in the discussion. Pair and share stages provide opportunities for all the students to talk. This technique is appropriate for all grade levels and class sizes (Lyman, 1981). This is similar to Ledlow (2001), the TPS technique encourages individual participation and is applicable across all grade levels and class sizes. TPS is also a low-risk technique which is suitable for both instructors and learners who are new to the cooperative learning approach. TPS is also a strategy that encourages student classroom interaction; it encourages a high degree of pupil responses and helps keep students on task (Ledlow, 2001).

Moreover, Robertson (2006) found that the use of the TPS technique could cause a high degree of students' response rather than the use of basic presentation method which refers to the teacher poses questions and the students' offer the response. This can be concluded that the TPS technique was designed to encourage the students to formulate their ideas and share with another students. It helps to stimulate the students' classroom participation.

Furthermore, TPS is effective as a warm-up for whole class discussion. The "Think" provides the students to stop and reflect before speaking. On the other hand, it gives students a chance to collect and organize their ideas. The "Pair" and "Share" are the stages that stimulate the students to compare and discuss their understanding with the classmates, and to rehearse their response first in a low-risk situation before sharing with the whole class. Providing this technique to the students tends to improve their contributions and generally increases the students' motivation to speak in a larger group (Sari, 2012).

Based on the explanations above, it can be summarized that Think-Pair-Share is one of the well-known techniques that aims to encourage the students to participate in class. It stimulates the students to collaborate in class, exchange and discuss their ideas, and share with their classmates. It is a low-risk technique. The teachers can implement this technique to all grade levels and every class size of students.

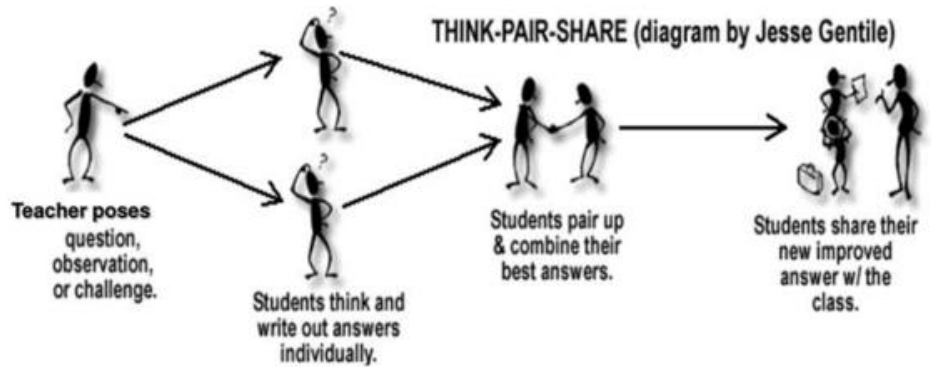

Figure 1. Think-Pair-Share Steps

Source: Gentile (2008 cited in Lasnami, 2013, p. 7)

From the Figure 1, Lasnami (2013) explained that the TPS technique includes three main steps; time for thinking, time for sharing ideas and knowledge with a partner, and time for each pair to share back to a larger group. Moreover, Ledlow (2001) explained TPS as, Think-think about your answer individually, Pair-pair with a partner and discuss your answer, and Share-share your or your partners' answer, when called upon.

For EFL teachers, Arends (2008) suggested the step to make the pupil be active through Think-Pair-Share as (1) Thinking, which the teacher asks a question to the students related to the topic or lesson. Then, the teacher gives the students time to think about their responses individually and write out the answer. This is important for students' just to be quiet for a few moments and store their thoughts about the questions. They may write some thoughts and ideas in response to the question. (2) Pairing; the students team up with their classmates and share their answers for two or three minutes, or they work together to create a convincing answer. Lastly, (3) Sharing, the step that the teacher asks students to share their answers or ideas to all students in the class.

Lasnami (2013) explained three components of TPS as; Time for thinking for a correct and constructive answer. Time for pairing with their classmate to check the answers and exchange their ideas. Finally, time for sharing to the larger group. They could share their ideas, give and receive information from each pair, and comment on each 
other's answers.

In conclusion, the TPS technique prompts the students to think individually about a topic or answer to a question, pair with a partner to discuss or exchange the ideas, and share ideas with classmates. Discussing an answer with a partner serves to a larger group of participants, focuses attention and engages students in comprehending the reading material.

\subsection{The Think-Pair-Share technique on the reading context.}

Many researchers have employed the TPS technique into their reading class. Their findings are presented as; there were some difficulties during the reading class such as the students' ability in reading was low, they were nonacademic during the reading class, and they were noisy and not interested in the lesson (Sari, 2012). The limited vocabulary knowledge of the students is the main problem found in reading class (Maulida, 2017).

However, these situations were changed when the TPS technique was implemented into the reading comprehension class. The difficulties were minimized. Sari (2012) found that the use of TPS could improve students' reading skills. The students' ability in comprehending the text was improved. Their improvement included students were able to infer the meaning of the words, identify the main idea of the text, identify the reference of the text, find implicit information of the text, determine explicit information, and identify the communicative purpose of the text. Moreover, Fatkur (2017) compared the students' scores between the Direct Instruction method and the TPS technique. It was found that the students who were taught using TPS had higher scores than those who were taught using Direct Instruction. Therefore, I as a researcher in this study could summarize that the TPS technique was effective on reading comprehension. It can increase the students' ability in comprehending the text.

Moreover, not only the students' ability in reading comprehension was improved but also the classroom situation. Most of the students were active and communicative during the teaching and learning process, the students began more enthusiastic in reading class, and the students did not bother their friends. Moreover, TPS helped the students have higher motivation and interest in joining the reading class (Sari, 2012). It is similar to Maulida (2017), who stated that the TPS technique could level up the students' confidence. The students might hesitate to come forward voluntarily if they were alone. When they were with their partner, it was in contrast. They would be brave enough to show their ideas to others. Furthermore, the students became more active and creative when they implemented TPS in the class. When Fatkur (2017) examined the effectiveness of the TPS technique to teach reading comprehension. The findings revealed that the TPS technique not only gave opportunities for students to improve their reading comprehension but it also stimulated the students' motivation in reading. All students participated in classroom activities. They were able to communicate with their partner and friend to solve the problems related to the posed questions. They had a chance to speak, shared their own perspective, and developed their skill in working with others. They could improve their confidence by sharing their brief ideas to their classmates. This made the class come alive and cooperative. The students became more confident as well.

From the above information, it was found that many researchers examined the use of TPS in a reading context. The results of these studies indicate that the problems in reading can be minimized by using TPS. It can improve students' reading skill and the class situation. The students were active and enthusiastic. It provides students with more chances to talk and interact. It is better than working alone.

\subsection{Pattern on pairing configuration}

Pairing is one of the TPS steps. Ledlow (2001) explained that the Pair stage from TPS is for the learners to pair with a partner and discuss their answer or ideas. One of the advantages of pair-work is that it helps learners build positive interpersonal relationships and create a high level of academic solidarity and confidence (Storch, 2002). Therefore, there is widespread use of pair work in the education system. This is similar to Baleghizadeh and Farhesh (2014), who stated that to apply pair working and small groups working in their classroom has preoccupied teachers' minds for quite a long time.

When the students working in pairs, the study showed that they can scaffold each other's performance. However, the scaffolding may occur when pairs interact in the right pattern (Storch, 2002). Therefore, there are many studies conducted about the nature of group interaction. This has been the topic of extensive research in social psychology and general education. Here is an example study which is exploring many patterns of pair working. Storch (2002) conducted a study on the topic "Patterns of interaction in ESL pair work". The study examined the nature of the interaction of ESL students over a range of language tasks. This study revealed four patterns of interaction as shown in Figure 2 


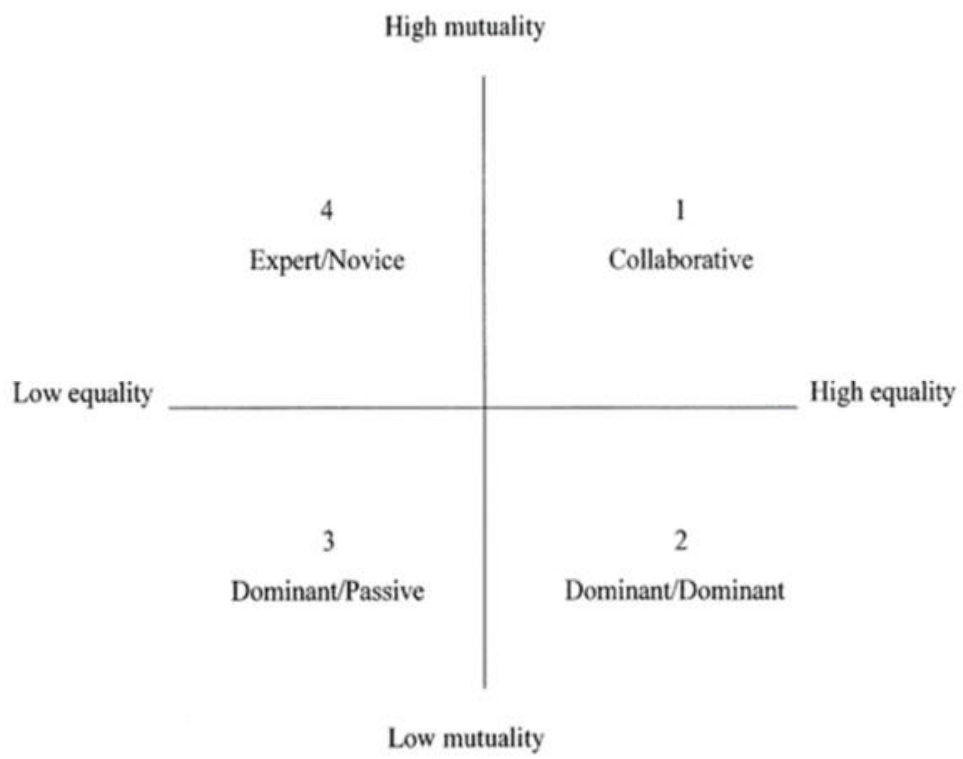

Figure 2. A model of dyadic interaction.

As shown in Figure 2, there are 4 quadrants that describe the patterns of interaction in pair work, focusing on the pair relationship and equality. Two indexes were used to distinguish among these four patterns of dyadic interaction. There are equality and mutuality. The term equality refers to the degree of control or authority over the task (Phelps, 1989). It also describes more than merely an equal distribution of turns or equal contributions but an equal degree of control over the direction of a task (Vanlier, 1996). Therefore, high equality refers to the situation where both participants take directions from each other. While the term mutuality is used to refers to the level of engagement with each other's contribution. High mutuality describes interactions that are rich in reciprocal feedback and a sharing of ideas (Damon \& Phelps, 1989).

Quadrant 1 was marked as "collaborative". Underwood and Underwood (1999) described the term collaborative as a pair working together. Erickson (1989) supported that the term collaborative is where the learners are willing to offer and engage with each other's ideas. The result in the collaborative quadrant leads to high equality and high mutuality in pair working (Storch, 2002).

Quadrant 2 was marked as "dominant/dominant." Both participants contribute to the task together. There is an unwillingness or inability to fully engage with each other's contribution. The result in this pattern leads to high equality but low level of mutuality. On the other hand, this pattern of interaction is marked by a high level of disagreements and an inability to reach consensus. That is, learners in each pair may contribute equally to the task, but there may be very little engagement with each other's contribution (Storch, 2002).

Quadrant 3 was marked as "dominant/passive." The dominant participants in each pair takes an authoritarian stance and seems to appropriate the task. The other participant seems to adopt a more passive, and submissive role. There is a little negotiation in this pattern of interaction because there are few contributions or challenges forthcoming from the more passive participant. It can be summarized that the level of equality and mutuality are both moderate to low (Storch, 2002).

For the last quadrant, the term "expert/novice" was used to describe the pattern of interaction situated in this quadrant. In this pattern of interaction, one participant seems to take more control over the task. In contrast with the dominant/passive scenario, this participant acts as an expert who actively encourages the other participant which is called the novice to participate in the task. Therefore, this quadrant was used to represent a pattern of dyadic interaction where there is moderate to low equality but moderate to high mutuality (Storch, 2002).

From the analysis of dyadic interaction in an ESL classroom, it was indicated that not all students work collaboratively when assigned to work in pairs on language tasks (Storch, 2002). Four patterns on pair work namely; collaborative, dominant/dominant, dominant/passive, and expert/novice have their own characteristics and are distinguished in terms of equality and mutuality (Damon \& Phelps, 1989). Therefore, it is the teachers' 
responsibility to select the pattern of pair configurations to apply to their students.

\section{Methodology}

This study was an action research which employed a qualitative research design. Classroom observation was conducted to explore the varieties phenomenon of Think-Pair-Share technique in reading comprehension. This could help the researcher to get a depth of information about the results of using TPS technique in improving students reading comprehension skill.

\subsection{Context of the study}

The participants were 22 students (11 males and 11 females). They were Thai EFL students who were studying in Grade 12, in a secondary school in eastern Thailand. They were selected by a purposive sampling method. The participants were studying in the science-mathematics program. They had at least 12 years of exposure to learning English. The level of using the English language of the students is basic user. They could understand simple spoken English with low speed, they could ask and answer simple questions and respond to simple statements on familiar topics. They could write simple sentences using limited vocabulary, understand very short, simple written English, and they had an adequate vocabulary to communicate in daily life or on familiar topics.

\subsection{Research instruments and Data collection}

(1) Lesson Plan: Four lesson plans were presented. Each lesson plan was designed for two periods (100 minutes). The TPS technique was implemented in each lesson plan in order to explore the phenomenon in each facet of the TPS technique in reading comprehension. There were three learning objectives in the lesson plans; (1) the students can read and comprehend the text. (2) The students can express and exchange their ideas related to the given topic. (3) The students can work in pairs and have interaction with their classmates.

The lesson plan was divided into three stages. First, the pre-reading stage was used for checking the students' background knowledge and allowing the students to do the "Think" step from the TPS technique. The students had to think and try to answer the pre-reading questions individually within a limited time. Next, while-reading stage, this stage was for "pairing". The students were asked to pair with a partner in the various patterns of pair configuration namely independent partner, dominant/dominant, and dominant/passive. Then, each pair of students helped each other to read, to comprehend the text, and did the task (if any). The last step was the post-reading stage. After the pair working, the teacher might ask each pair of students to do the "Share" step from the TPS technique. The students share their ideas or their understanding of the text to their classmates. The students were also asked to share their tasks related to the text. By this stage, the teacher could examine the students' ability in comprehending the text. Table 1 shows the different patterns of the TPS technique implemented in each lesson plan.

\begin{tabular}{|c|c|c|c|}
\hline & The "Think" stage & The "Pair" stage & The "Share" stage \\
\hline $\begin{array}{l}1^{\text {st }} \text { lesson } \\
\text { plan }\end{array}$ & $\begin{array}{l}\text { The time duration in this stage is } \\
22-3 \text { minutes. }\end{array}$ & Independent partner & $\begin{array}{c}\text { Share by answering the } \\
\text { questions }\end{array}$ \\
\hline $\begin{array}{l}2^{\text {nd }} \text { lesson } \\
\text { plan }\end{array}$ & $\begin{array}{c}\text { The time duration in this stage is } 5 \\
\text { minutes. }\end{array}$ & Dominant/Dominant & $\begin{array}{l}\text { Share by doing mind- } \\
\text { mapping. }\end{array}$ \\
\hline $\begin{array}{l}3^{\text {rd }} \text { lesson } \\
\text { plan }\end{array}$ & $\begin{array}{l}\text { The time duration in this stage is } \\
\qquad 10 \text { minutes }\end{array}$ & Dominant/Passive & $\begin{array}{l}\text { Share by retelling the } \\
\text { passage }\end{array}$ \\
\hline $\begin{array}{l}4^{\text {th }} \text { lesson } \\
\text { plan }\end{array}$ & $\frac{\text { The time duration in this stage is }}{10 \text { minutes }}$ & Independent partner & $\frac{\text { Share by answering the }}{\text { questions }}$ \\
\hline
\end{tabular}

Table 1. The different patterns of the TPS technique implemented in each lesson plan.

Table 1 shows the different patterns of the TPS technique implemented in each lesson plan. In the first lesson plan, the participants had 2-3 minutes for the "Think" stage. The participants used this time to answer the prereading questions. Then, the participants paired up with their partner. In this stage, they had a chance to select their 
own partners. After that, each pair worked together to read and comprehend the passage and answered the questions in the "Share" stage. By answering the post-questions, the teacher can examine the students' general comprehension of a reading passage, and the students can review the information from the passage too.

For the second lesson plan, the participants had 5 minutes for the "Think" stage. The teacher posed some questions that led students to think about the passage for five minutes and the participants used this time for answering the pre-reading questions. Then, it was the "Pair" stage. The participants paired up with their partner in order to read the passage and worked as a team. In this step, the participants paired up with the student that was selected by the teacher. The teacher matched a dominant student to work with a dominant student. In this study, the dominant students are referred to as effective students. Therefore, the researcher matched the students who had the same level of efficiency in English to work together. Lastly, was the "Share" stage. Each pair of students did the mind-mapping and shared with their classmates. This task allowed the researcher to examine the students' structure and order of their thinking, and their understanding of the passage through creating a visual representation of concepts.

In the third lesson plan, the participants spent 10 minutes for the "Think" stage. The teacher posed some questions that led students to think about the passage. The students had to think individually about the questions based on their background knowledge. Next, was the "Pair" step. The participants paired up with their partner in order to read the passage and work as a team. In this step, the participant paired up with the student who was selected by the teacher. The teacher divided each pair by matching a dominant student with a passive student. The dominant refers to the students who have efficiency in English while the passive refers to the students who have less efficiency in English. Lastly, it is the "Share" stage. Each pair of students had to share their understanding of the passage by retelling the passage to their classmates.

Retelling is considered to be post-reading recall in which readers tell what they remember both orally and with illustrations (Kalmbach, 1986 as cited in Han, 2005). Assigning the students to do this task challenges them to communicate what they have learned to others and the teacher could examine how students consider the text, and how they understand the text.

For the fourth lesson plan, the think, pair, and share stages in this session were selected from the best stage of sessions 1-3. After finishing each session, the researcher analyzed the data in order to find the most effective think, pair, and share stage. Then, put them in the last session. The participants had 10 minutes for the "Think" stage. They used this time to answer the pre-reading questions. Then the participants paired up with their partner. In this stage, it was independent partner. It means that the participants had a chance to select their own partners. After that, each pair of participants worked together to read and comprehend the passage and answer the postreading questions. Then they shared their answers in the "Share" stage. By answering the post-questions, the teacher can examine the students' general comprehension of a reading passage, and the students can review the information from the passage too

(2) Video record classroom observations: there were four classroom observations held in this study. The researcher taught reading comprehension by using the TPS technique, the researcher wanted to observe the phenomenon in each stage of the TPS technique. However, the researcher could not teach the lesson, observe the phenomena, and take notes simultaneously. Therefore, classroom observations were video recorded while the researcher processed one of the research instruments in this study.

(3) Researcher's reflection: The researcher's reflections on the phenomena and the class interaction during the teaching process. The researcher immediately took notes after finishing each class. The reading comprehension in class, the classroom environment, the phenomenon during implementation for each step of the TPS technique, and how the students deal with the activities that were provided by the teacher are the aspects that the researcher was interested in and noted down.

The qualitative data collection took place during May-July 2019 which was the first semester of the academic year 2019. The researcher started the data collection by doing classroom observations. The teaching process was video recording during class. The observations aimed to investigate the students' ability to comprehend the text in each lesson plan and explore the phenomenon in each step of the TPS technique.

The researcher noted the reflections by using the data from the observations about the students' ability to comprehend the text in each lesson plan and the effect of TPS from each session. 


\subsection{Content analysis}

Classroom observations and the researcher's reflection analysis

The qualitative coding data analysis started with transcribing the information from the video recordings. In this step, the researcher focused on the data about students' ability in comprehending the text and the phenomenon in each step of the TPS technique. The next step was coding the data into themes. The last step was analyzing the contents of the information.

The researcher analyzed the data from the classroom observations and the researcher's reflection in each session as three parts, which were the pre-reading stage, while-reading stage, and post-reading stage.

For the pre-reading stage, the data was separated into various issues as follow, the phenomenon when the participants followed the "Think" stage from the TPS technique. The appropriate time duration used in the prereading stage of each session. The participants' background knowledge related to the topic of each passage. The participants' ability in answering the pre-reading questions was the main activity in this stage.

The issue that was analyzed from the while-reading stage was the phenomenon in the pair work. The data in this stage showed the situation during working in pairs in all patterns of pair configuration. It showed the participants' collaboration and interaction in each pair. Lastly, it showed the participants' ability to read and do the task work.

For the post-reading stage, the data was analyzed into the following issues; the participants' ability to read and comprehend the reading passage and the phenomenon when the participants shared their ideas with their classmates.

Moreover, the classroom observations were used to analyze the data about the situation of reading comprehension in each session, such as the reading difficulty (if any) and how participants deal with it. It showed how TPS technique affects the participants' reading comprehension skill too.

\subsection{Ethical considerations}

The researcher was concerned about the ethics of the study. Before conducting the data collection, consent forms were sent to the school's director in order to asked permission to collect the data and to use the institution's name. The aims of the study and the time duration of collecting the data were clearly explained to the school director. After the school's director approved the consent forms, the researcher informed the head of the foreign language department about the permission and the time duration for collecting the data.

The participants were asked to sign the "Informed Consent for Participation in Research" form. The aims of the study, the process and the time duration of collecting the data were informed to the participants. The participants were informed about their right to end their participation without any penalty, and their identity will be kept confidentially. The participants were informed that the video recording during the data collection and the findings from the collection were not related to their grades in E33101 (English 5).

\section{Findings and Conclusion}

To address the research question "What is an appropriate Think-Pair-Share model in reading comprehension for grade 12 students?", the lesson plans were conducted and applied to the participants. The results from the observations and the researcher's reflection are as below.

\section{1 "Thinking” Stage}

From the theory, the thinking stage from the TPS technique is the stage that the teacher asks questions to the students which are related to the topic or lesson. Then, the teacher gives the students time to think, to respond individually, and write out the answers. On the other hand. this stage provides the students a time to store their thoughts about the questions (Arends, 2008).

In this study, the researcher focused on the duration of time for individual thinking. The participants had to answer the pre-reading questions. There were six equal questions in each stage; however, there were differences in the length of time, 2-3 minutes, 5 minutes, and 10 minutes. It was found that 2-3 minutes (session 1) and 5 minutes (session 2) of thinking time was too short to achieve the activity. Participants could not answer all the prereading questions in time. In contrast with 10 minutes (session 3), the researcher found that all of the participants 
could answer all the questions in time.

Therefore, from the all sessions in the data collection process, the researcher decided to propose the time duration during the "Think" stage for ten minutes. This length of time provides the students with adequate time for individual thinking about the passage. They do not have to hurry to do the intended activities.

Ten minutes of time duration in think stage was a proposing model in this study not only because it provides the adequate time for the students to finish the pre-reading activity by thinking individually along the pre-reading questions, but the time was also enough to stimulate the student's interesting and allow them to check their prediction to the passages,

However, 2-3 minutes or 5 minutes could also be appropriate time duration. This was because the aim of the pre-reading stage is for the teacher to prepare the students for the text that they are going to read (Aebersold \& Field, 2003 as cited in Gumus, 2009). Moreover, Nuttal (1982, as cited in Rasheed, 2014) stated that the questions in the pre-questioning activity do not ask to test the students' comprehension but asks to stimulate the student's interesting and to check their prediction.

It was noted that this activity stimulated the students to paid attention and interest in the reading passages, it stimulated them to use their background knowledge, this made them eager to read the whole passage. Moreover, the findings showed that the students had the ability to comprehend the text and they achieved the learning objectives of the lesson at the end of the class. It could summarize that with all types of the duration of time in this study, the pre-questioning stage could support the learning process. The students achieved the learning objective even though they could not finish the pre-reading questions. Therefore, if the class has limited time than in this study, 2-3 minutes or 5 minutes might be more appropriate.

However, the suitable duration of time during the "Think" stage might be different in other cases. It depends on the variables such as the number of questions that the teacher poses or the difficulty of issues that the teacher gives to the students. Students' background knowledge and their promptitude are other factors that associate with the length of time in this stage. The ten minutes of proposing time in this study is just a guideline for the teacher. It does not cover for all situations.

\section{2 "Pairing” Stage}

In the stage of "Pair", the researcher focused on the pattern of pair configuration. There were three patterns in this study; 1) Independent partner which means the participants had a chance to select their partner by themselves. 2) Dominant/Dominant which means that the teacher matched the partner for the participants by pairing the same level of effective students together. Lastly, 3) Dominant/Passive which refers to one participant took an authoritarian stance while another participant played a subservient role. The conclusions are as follows.

The appropriate pattern of pair dyadic proposed in this study was the "independent partner". The independent partner means the participants have a chance to find their partner by themselves. It could be called a collaborative partner. Storch (2002) defined that there are the willing to offer and engage between the learners in this dyadic. This leads to high equality and high mutuality. Therefore, the phenomenon in pair working showed that the participants were satisfied with their partner. They could work with their close friend who was selected by themselves. Then they became good teamwork. Their working process was quite smooth too.

For the other patterns of dyadic used in this study; the dominant/dominant as well as the dominant/passive, it does not mean that they are not effective. From the findings, it was found that the participants were satisfied with their partner in all patterns of pair configuration. They could work with their friends. They became good teamwork. Moreover, their working process was smooth. However, some phenomenon in the dominant/dominant as well as the dominant/passive patterns showed that although they could work together the degree of collaboration in each pair was different from the "independent partner".

For the dominant and dominant, the participants consulted each other less than the previous pattern. However, they finally achieved the task goals. This related to the results of Storch (2002) who clarified that the member in each pair works equally to accomplish the task but they have less engagement in each pair. On the other hand, there is high equality but a low level of mutuality in this style of pattern.

For the dominant and passive, the students could achieve the same task goals as the first two patterns. However, the level of collaboration was quite different. The main role was belonging to the dominant students while the passive student helped less. This is similar to the findings from Abdurrahman, Susilawati, and Arifin 
(2011). They declared that when pairing the superior student with the lower skill partner. It was found that the clever one in each pair took the whole activities. They did not give any chance to their partner. Storch (2002) also stated that there is a little negotiation between the dominant and the passive because there are few contributions from the passive students. This leads to the conclusion that dominant/passive bring low equality and low mutuality.

\section{3 “Sharing” Stage}

In the stage of share, the researcher focused on the process of the participants sharing their understanding of the text. There were three types of sharing; answering the question, doing the mind-mapping, and making a retelling story. It was found that all three processes could examine the students' understanding toward the reading passage.

However, in this study, the researcher proposed "answering the questions" to be the method of sharing from the TPS steps. Since this process was not time-consuming. On the other hand, it took the shortest time to made an assessment. The researcher could evaluate all the participants' understanding at the same time. Furthermore, the participants could answer the questions without any help from the researcher whereas doing my mapping and retelling the passage required some help from the teacher.

This finding conforms to Ledlow (2001) who stated that the stage of "share" from the TPS technique is for the learners to share their ideas when called upon. It was also similar to Arends (2008) who suggested that the teacher asks students to share their answers or ideas with all students in the class during the "Sharing" stage.

\subsection{The phenomenon of reading comprehension during the implementation of the Think-Pair-Share technique}

When implementing the TPS technique into the reading comprehension class, the situation along four sessions in this study showed that most of the participants did not face the difficulties in reading. They had the ability in comprehending the text. They could understand the main idea and the details of the passage. Furthermore, the students did not face the huge difficulties in vocabulary knowledge and grammatical structure too.

There were some cases that showed the students encountered with vocabulary problem. However, in pair working, they helped together to overcome the problems they got. This can be summarized that when implementing the TPS technique into the reading comprehension class, the stage of "pair" working could help the students to resolve their difficulties without or less help from the teacher. This was similar to Maulida (2017) who proposed that the TPS technique can be one of the solutions to both helps the students solve their difficulties in reading comprehension and helps the teachers by providing an appropriate technique to teach reading comprehension. Therefore, when applying the TPS technique into the reading comprehension class, the results from this study showed that the participants faced with fewer difficulties.

The students in this study also worked in a relaxed environment. This condition occurred when the students working in pairs during the "pair" stage from the TPS technique. Especially, whenever the students pair up with their close friends, they could exchange and discuss their ideas together with the trustworthiness and confidence. It can be claimed that, working in pair promoted cooperative learning.

All in all, the results from this study could summarize that using TPS technique in the reading comprehension class could minimize some difficulties in reading. The students' ability in reading increased. It provided the students to pay attention to the lesson. It could promote speaking skills too. It forced students to interact with their classmate likewise the study from Maulida (2017) who revealed that the TPS technique was an interesting and helpful technique which helped English teachers a lot in the class. It also helped learners to be actively engaged in classroom activity.

\section{Discussion}

There are many researchers used the Think-Pair-Share technique as a solution to both helps the students solve their difficulties in reading comprehension and helps the teachers provide appropriate teaching process to teach reading comprehension. The results from this study showed that using the TPS technique in a reading comprehension class could minimize some difficulties in reading. It provided the students to pay attention to the reading passages. It could promote students' speaking skills too. It forced them to interact with their classmates. It also helped learners to actively take part in the classroom activity.

However, to utilize these advantages of the TPS technique, the teacher should provide the appropriate step in 
teaching. Therefore, in this study the researcher proposes the model of TPS as follows; (1) In the "Think" stage, students are given time to think individually about the posed questions for 10 minutes. However, this is just a guideline for the teachers. By this study is limited to make the students answered the pre-reading questions in the "Think stage" which required only 10 minutes. Moreover, the class with more limited time than in this study might suit with 2-3 minutes or 5 minutes. However, the suitable duration of time during the "Think" stage could be different from this. It depends on activities which would be held in this stage. However, whatever activities it will be held, the thinking process is supposed to be promoted. (2) In the "Pair" stage, if the teachers want to promote interaction and collaboration in each pair, the students should have a chance to select their partner by themselves. This can be called an "Independent partner". When the students work with the partner they choose, the degree of collaboration will increase. Lastly, (3) in the "Share" stage, the activities used in this stage should examine the comprehension skill of the students. The researcher then proposes "answering the post-reading questions" to be used in this stage. This kind of activity is easy to evaluate. The teachers can evaluate the understanding of all the students at the same time. It is not time-consuming. It is appropriate for teachers who have limited time. Not only examined the students' ability in comprehending the passages, this stage should also challenge the students' communicative skill too. By sharing their own ideas or answers to their classmates, it automatically forced the students to practice their speaking skill.

All in all, implementing reading comprehension lesson with the TPS technique into the class could bring the good phenomenon in learning. It can minimize the students' reading difficulties. It promotes the reading comprehension skill. It gives a chance to students to have time to think individually. This promotes the thinking process. The TPS technique also provides pair working which causes good results such as the students' collaboration, problem solving, and increase their communicative skill. Lastly, it offers the opportunity to the teachers to examine the students' ability in comprehending the passage through the process of "Share". By this stage, the students can get the feedback from the teacher and get a chance to revise their ideas if they have misunderstanding about the lesson.

\subsection{Limitations of the study}

This proposed model of TPS for reading comprehension does not fit every context. It was appropriate in this study for the 22 participants in grade 12. However, it might be suitable for a class which has a similar context with this study. Moreover, the findings from this study do not affect the casual relationship of the TPS technique. There was no control group in this study.

Another limitation was found during the data collection. There were 22 participants in this study, and when only one participant was absent, it was impossible to collect data. This made the data collecting process longer than expected.

\subsection{Recommendations}

These recommendations may be useful for future researchers, teachers, and students. (1) The duration of time during the "Think" stage should be associated with the activities that are provided in this session. The future researchers and the teachers may provide a different duration of time in this stage but be careful that the time and the activities could get together. Moreover, the activities in this session must promote the students' thinking process.

(2) Pairing with their friends independently during the "Pair" stage can increase their ability to attend to the assigned tasks. It also promotes student interaction. However, this does not mean that other types of pairing are not appropriate.

(3) There are many ways to examine students" comprehension of the text through the "Share" stage. Answering the post-reading questions, doing mind-mapping, and retelling a passage are some examples of sharing. The teachers and future researchers can implement other styles of sharing in this stage.

(4) For future researchers, there are many aspects that are not covered in this study. I as a researcher would like to recommend that researchers who are interested in this field examine other aspects such as the type of passages, gender awareness matching, level of the participants, and method to examine the students' ability in understanding the text. Different variations can cause different results. Then you can propose another suitable model of the TPS technique in reading comprehension class. These also make the study gain more meaningful and representative results. Moreover, future researchers can also implement the TPS technique for other skills, especially speaking skills. The TPS technique can promote the interaction of the students. It automatically forces the students to talk and exchange ideas with their classmates. 


\section{References}

Abdurrahman, E., Susilawati, E., \& Arifin, Z. (2011). Improving Students Ability in Reading Comprehension Through Cooperative Learning (Think Pair Share). Journal Pendidikan dan Pembelajaran Untan, 2(10), 1-11

Adunyarittigun, D. (2002). An investigation of factors affecting English language reading success: A case study of an EFL college reader. Thammasat Review, 7(1), 24-271.

Al Rasheed, H. S. (2014). Examining the Effectiveness of Pre-Reading Strategies on Saudi EFL College Students' Reading Comprehension. English language teaching, 7(11), 79-91.

Alsubaie, M. A. A. (2014). An exploration of reading comprehension challenges in Saudi Arabian University EFL students. Doctoral dissertation, Education, The University of Exeter.

Arends, R. (2008). Learning to teach (9th ed.). Columbus: McGraw-Hill Education.

Baleghizadeh, S., \& Farhesh, S. (2014). The impact of pair work on EFL learners' motivation. MEXTESOL Journal, 38(3), 1-11.

Bell, J. (1988). Improving students learning and college teaching. Howard: Howard Community College.

Birsch, J. R. (2011). Multisensory teaching of basic language skills (3rd ed.). Baltimore, MD: Paul H. Brookes.

Block, C. C. (2004). Teaching comprehension: The comprehension approach. Boston, MA: Pearson Education.

Bond, G., Tinker, M., Wasson, B., \& Wasson, J. (1989). Reading difficulties: Their diagnosis and correction (6th ed.). New Jersey: Prentice Hall.

Damon, W., \& Phelps, E. (1989). Critical distinctions among three approaches to peer education. International Journal of Educational Research, 58, 9-19.

Durkin, D. (1993). Teaching them to read (6th Ed.). Boston: Allyn \& Bacon

Erickson, F. (1989). Learning and collaboration in teaching. Language Arts, 66, 430-441.

Fatkur, R., \& Retnaningsih, H. W. (2017). THE EFFECTIVENESS OF THINK-PAIR-SHARE TECHNIQUE (TPS) TO TEACH READING COMPREHENSION (An Experimental Study at The Eight Grade Students of SMP N 1 Juwiring in 2013/2014 Academic Year) (Doctoral dissertation, IAIN Surakarta).

Gumuş, P. (2009). The effect of the timing of pre-reading activities on students' reading comprehension (Doctoral dissertation, Bilkent University).

Han, J. A. (2005). Retelling as an effective reading comprehension strategy for young ESL learners. Masters' thesis, English, Iowa State University.

Lasnami, S. (2013). Investigating the impact of using think-pair-share co-operative learning technique on students' interaction in an EFL classroom: Case study: Second year LMD students of English at Bejaia University. Masters' thesis, Language Sciences and Didactics, Faculty of Arts and Languages, University Abderrahmane Mira of Bejaia.

Ledlow, S. (2001). Using think-pair-share in the college classroom. Retrieved from https://kaneb.nd.edu/assets/137953/think_pair_share_tips.pdf

Lyman, F. (1981). The responsive classroom discussion. I: Anderson, AS (Ed.), Mainstreaming Digest. College Park, MD: University of Maryland College of Education.

Lyman, F. (1992). Think-pair-share, thinktrix, thinklinks, and weird facts: An interactive system for cooperative learning. In N. Davidson \& T. Wor- sham (Eds.), Enhancing thinking through cooperative learning (pp. 169-181). New York: Teachers' College Press.

Maulida, F. (2017). The use of think-pair-share in teaching reading comprehension. ELT Forum: Journal of English Language Teaching, 6(1), 49-58.

Maulida, F. (2017). The use of think-pair-share in teaching reading comprehension. ELT Forum: Journal of English Language Teaching, 6(1), 49-58.

Medjahdi, W. (2015). Reading comprehension difficulties among EFL learners: The case of third-year learners at Nehali Mohamed Secondary School. Masters' thesis, Language Studies, Faculty of Liberal and Language, University of Tlemcen.

Narkprom, N., Poosiripinyo, V., \& Saito, S. (2016). An investigation of English problems of 4th year English major students in the Faculty of Education, Petchabun Rajabhat University. In the Proceeding of the 3rd Petchabun Rajabhat University National Conference (pp. 176-185). Petchabun: Petchabun Rajabhat University. 
Pressley, M. (2000). Comprehension instruction: What makes sense now, What might make sense soon. Retrieved from https://pdfs.semanticscholar.org/7585/ 89eade45b7d230fdd7acca8dd5b65524dc07.pdf?_ga=2.20068155.2031827784.1576913803166696373.1576913803

Rayner, K. et al. (2001). Eye-Movement Control in Reading: Word Predictability Has Little Influence on Initial Landing Positions in Words. Vis. Res, 41, 943-954. http://dx.doi.org/10.1016/S0042-6989(00)00310-2

Robertson, K. (2006). Increase Students Interaction by Think-Pair-Share Technique. Mexico City: Colorin Colorado.

Sari, R. A. (2012). Improving students' reading skill by using think-pair-share (TPS). Doctoral dissertation, Universitas Sebelas Maret Indonesia.

Storch, N. (2002). Patterns of interaction in ESL pair work. Language learning, 52(1), 119-158.

Underwood, J., \& Underwood, G. (1999). Task effect on cooperative and collaborative learning with computers. In K. Littleton, \& P. Light (Eds.), Learning with computers: Analysing productive interaction (pp. 10-23). London: Routledge.

Van Lier, L. (1996). Interaction in the language curriculum: Awareness, autonomy and authenticity. London: Longman.

Wahjudi, A. (2010). Interactive post-reading activities that work. Bahasa dan Seni: Jurnal Bahasa, Sastra, Seni, dan Pengajarannya, 38(1), 84-92. 